\title{
FLORÍSTICA E ESTRUTURA DE DUAS COMUNIDADES ARBÓREAS SECUNDÁRIAS COM DIFERENTES GRAUS DE DISTÚRBIO EM PROCESSO DE RECUPERAÇÃO ${ }^{1}$
}

\section{FLORISTIC AND STRUCTURE OF TWO SECONDARY ARBOREAL COMMUNITY WITH DIFFERENT DISTURBANCE DEGREE IN RECOVERY PROCESS}

\author{
Elaine Vivian Oliva ${ }^{2}$ Carlos Bruno Reissmann ${ }^{3}$ Renato Marques ${ }^{4}$ Jonas Eduardo Bianchin $^{5}$ Cilmar \\ Antônio Dalmaso ${ }^{6}$ Etienne Winagraski $^{6}$
}

\begin{abstract}
RESUMO
Este trabalho teve como objetivo caracterizar a composição florística e a estrutura da comunidade arbórea de áreas em processo de recuperação ambiental no município de Bocaiúva do Sul-PR. A produção e divulgação de dados e informações sobre a florística e fitossociologia da cobertura florestal em duas áreas com condições ambientais e intervenções distintas é uma contribuição relevante para compreender a dinâmica na estrutura arbórea em áreas de recuperação ambiental. Para isso, foram selecionadas duas áreas com distintos graus de degradação: Floresta Secundária Inicial (FSI), área na qual houve corte raso, isto é, retirada das camadas superficiais do solo e revegetação com Mimosa scabrella Benth; e Floresta Secundária Avançada (FSA), que representa um fragmento de Floresta Ombrófila Mista em que houve exploração seletiva de espécies de interesse comercial. A amostragem da vegetação foi realizada em 10 parcelas de 150 $\mathrm{m}^{2}$ em cada área $(0,15 \mathrm{ha})$, nas quais foram mensurados todos os indivíduos arbóreos, incluindo as árvores mortas com circunferência a altura do peito (CAP) igual ou superior a $15 \mathrm{~cm}$. Na FSI, foram amostradas 40 espécies pertencentes a 24 famílias, enquanto na FSA foram amostradas 57 espécies pertencentes a 27 famílias botânicas. Os resultados apontaram que a estrutura da vegetação na FSA é distinta da FSI, com menor densidade de árvores, maior área basal e diversidade florística.
\end{abstract}

Palavras-chave: Fitossociologia; florestas secundárias; florestas de restauração; revegetação.

\begin{abstract}
This work aimed to characterize the floristic composition and structure of the tree community of areas in the process of environmental recovery in the municipality of Bocaiuva do Sul, PR. The production and dissemination of data and information about floristic and phytosociology of forest cover in two areas with distinct environmental conditions and interventions, is a relevant contribution to understanding the dynamics in tree structure in areas of environmental recovery. For this, two areas with different degrees of degradation were selected: Initial Secondary Forest (FSI), area in which there was a clear cut, removal of the superficial layers of the soil and revegetation with Mimosa scabrella Benth; and Advanced Secondary

1 Artigo extraído da tese da primeira autora apresentada ao Programa de Pós-Graduação em Engenharia Florestal da Universidade Federal do Paraná.

2 Bióloga, Dr., Universidade Federal do Paraná, Av. Pref. Lothário Meissner, 900, Jardim Botânico, Campus III, CEP 80210-170, Curitiba (PR), Brasil. Bolsista CAPES. elainevivian_bio@hotmail.com

3 Engenheiro Florestal, Dr., Professor Colaborador da Universidade Federal do Paraná, Rua dos Funcionários, 1540, CEP 80035-050, Curitiba (PR), Brasil. karlbreis@yahoo.com.br

4 Engenheiro Florestal, Dr., Professor dos Programas de Pós-Graduação em Ciência do Solo e Engenharia Florestal, Universidade Federal do Paraná, Rua dos Funcionários, 1540, Campus I, CEP 80035-050, Curitiba (PR), Brasil. Bolsista do CNPq.rmarques@ufpr.br

5 Engenheiro Florestal, Dr., Universidade Federal do Paraná, Av. Pref. Lothário Meissner, 900, Jardim Botânico, Campus III, CEP 80210-170, Curitiba (PR), Brasil. Bolsista CAPES. jonasbianchin@gmail.com

6 Engenheira(o) Florestal, MSc., Doutoranda(o) do Programa de Pós-Graduação em Engenharia Florestal, Universidade Federal do Paraná, Av. Pref. Lothário Meissner, 900, Jardim Botânico, Campus III, CEP 80210-170, Curitiba (PR), Brasil. Bolsista CAPES. cilmard@gmail.com / etienne.winagraski@gmail.com
\end{abstract}

Recebido para publicação em 16/06/2015 e aceito em 31/07/2017

Ci. Fl., v. 28, n. 3, jul. - set., 2018 
Forest (FSA), which represents a fragment of Mixed Ombrophilous Forest where there was selective exploitation of species of commercial interest. Vegetation sampling was carried out in 10 plots of $150 \mathrm{~m}^{2}$ in each area $(0.15 \mathrm{ha})$, where all trees including dead trees with a diameter at breast height (DBH) equal or greater than $15 \mathrm{~cm}$. In the FSI, 40 species belonging to 24 families were sampled, while in the FSA, 57 species belonging to 27 botanical families were sampled. The results showed that the vegetation structure in FSA is different from FSI, with lower tree density, higher basal area and floristic diversity.

Keywords: Phytosociology; forest restoration; secondary forest; revegetation.

\section{INTRODUÇÃO}

A meta da restauração é reconstituir um ecossistema que seja o mais semelhante possível ao original, de modo a criar condições de biodiversidade renovável, através da qual a reprodução seja garantida e a diversidade genética em suas populações possibilite a continuidade de evolução das espécies (KAGEYAMA; GANDARA, 2006). Segundo Rodrigues et al. (2009), a dificuldade de reproduzir a complexidade de uma floresta na recomposição de ambientes degradados levou os pesquisadores a procurarem entender melhor a dinâmica da floresta tropical, em especial a maneira pela qual se dá o processo de regeneração natural. Os estudos sobre a regeneração natural são essenciais para a compreensão da dinâmica da vegetação (BARREIRA et al., 2002) e para a elaboração de planos de recuperação de áreas degradadas.

Um trabalho de recomposição deve envolver preocupações com a composição florística, a estrutura, a reprodução e autorregeneração da floresta (KAGEYAMA; CASTRO, 1989). Diversos pesquisadores com base em teorias propõem modelos de recomposição com técnicas e metodologias próprias. A recomendação de modelos que utilizam os conceitos relacionados à sucessão secundária foi indicada em diversas situações (REIS; ZAMBONIN; NAKAZONO, 1999; RODRIGUES; GANDOLFI, 2004; RODRIGUES et al., 2011), sendo uma das preferidas pelos gestores ambientais pelo seu menor custo e maior eficiência.

A análise da florística e estrutura da comunidade arbórea de ecossistemas restaurados ou em processos de restauração é indicador eficiente para impulsionar os conhecimentos ecológicos desses ambientes, avaliar e monitorar as fases de sucessões do processo de restauração da vegetação, bem como promover avanços em pesquisas subsequentes (DARONCO; MELO; DURIGAN, 2013; MIRANDA NETO et al., 2012).

Conhecer a composição e a estrutura florística do estrato regenerativo, após processos antrópicos e sucessão inicial da vegetação, e a comparação desse estrato com a estrutura da vegetação adulta, pode fornecer informações fundamentais referentes à dinâmica ambiental (MENDES, 2002). Muitas vezes, os grupos funcionais, também abordados como categorias e guildas ecológicas, podem complementar ou substituir o levantamento florístico no monitoramento de áreas em recuperação.

Em áreas florestais, quando as condições ecológicas são adequadas, a regeneração ocorre naturalmente, porém, em áreas degradadas, devido à alteração dessas condições, a intervenção antrópica é necessária para a recuperação e posterior restauração florestal, sendo utilizado o plantio de mudas de espécies nativas da região (VENTUROLI; VENTUROLI, 2011). O plantio dessas árvores promove uma eficiente cobertura, permitindo um ambiente favorável à colonização e desenvolvimento de novas espécies (GUILHERME, 2000).

Em áreas de sucessão secundária, a composição florística vai se modificando e tornando a vegetação cada vez mais complexa e diversificada. Portanto, estudos referentes à regeneração natural são imprescindíveis para melhor entendimento dos mecanismos de transformação da composição florística e estrutura da floresta (SILVA et al., 2010), bem como para restaurar, estabilizar e conservar ecologicamente os ecossistemas naturais.

Assim, este trabalho objetivou avaliar a regeneração da comunidade arbórea em área de restauração ambiental, por meio da caracterização da composição florística e da estrutura fitossociológica de duas áreas de floresta secundária submetidas a diferentes graus de distúrbio em Bocaiúva do Sul-PR. 


\section{MATERIAL E MÉTODOS}

\section{Área de estudo}

O estudo foi realizado no município de Bocaiúva do Sul-PR $\left(25^{\circ} 8^{\prime} 18,55^{\prime \prime}\right.$ S e $48^{\circ} 52^{\prime} 31,76$ ”O $)$ (Figura 1). As áreas de estudo se encontram aproximadamente a $800 \mathrm{~m}$ de altitude, com relevo ondulado que pode variar para fortemente ondulado. O clima da região, segundo a classificação de Köppen, é caracterizado como $\mathrm{Cfb}$ (temperado), com as estações de verão e inverno bem definidas. A temperatura média no mês mais frio é abaixo de $18^{\circ} \mathrm{C}$, enquanto a temperatura média no mês mais quente é abaixo de $22^{\circ} \mathrm{C}$ (INSTITUTO AGRONÔMICO DO PARANÁ, 2015). Conforme dados climáticos obtidos junto ao Sistema Meteorológico do Paraná (SIMEPAR), a pluviosidade média anual nos últimos 7 anos na região foi de $1586 \mathrm{~mm}$.

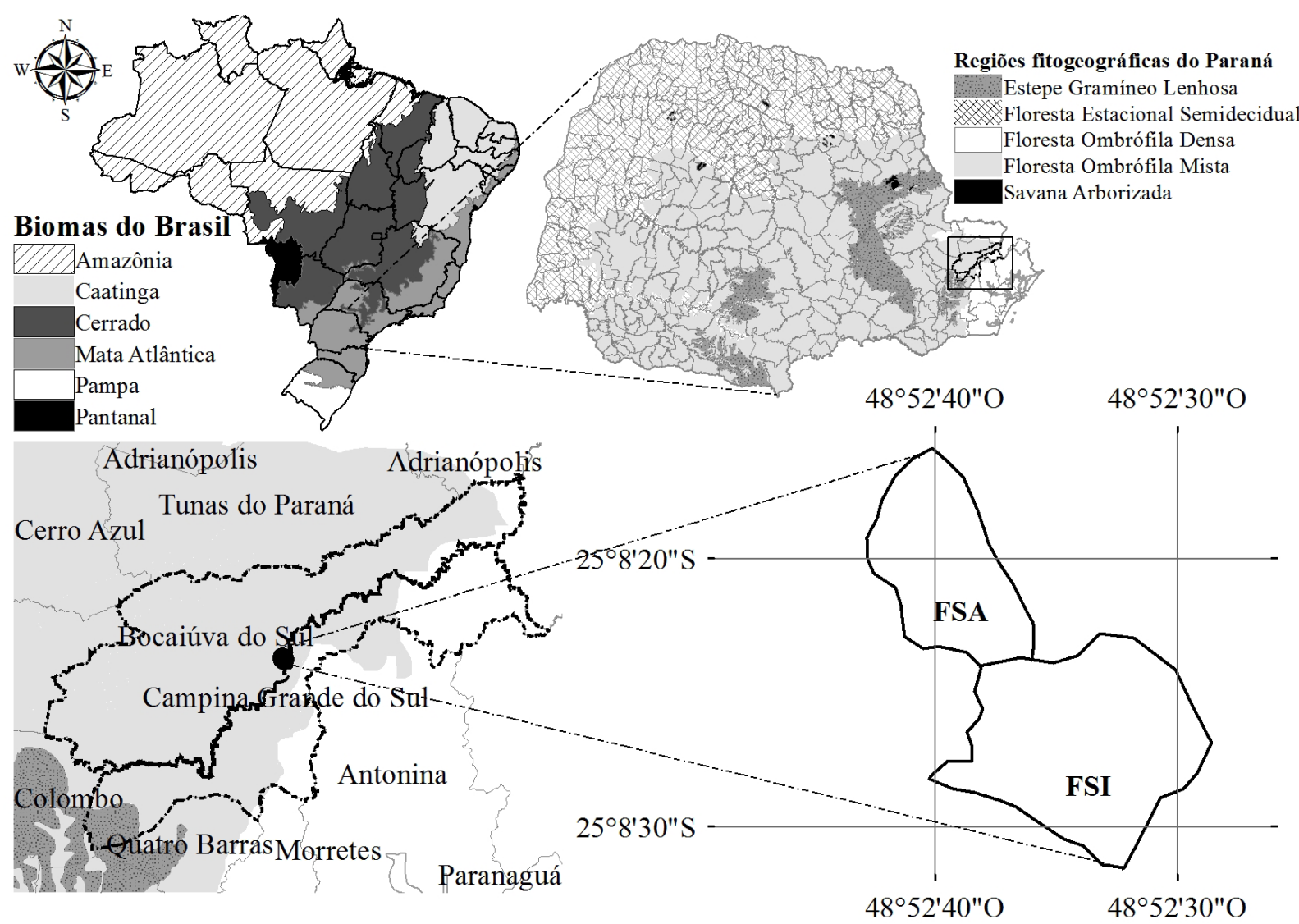

FIGURA 1: Localização das áreas de estudo no município de Bocaiúva do Sul-PR.

FIGURE 1: Study area location in the municipality of Bocaiúva do Sul, PR state.

A vegetação da região é classificada como um ecótono, pela presença de Floresta Ombrófila Densa e Floresta Ombrófila Mista (IBGE, 2012), predominando espécies desta última fitofisionomia. A Floresta Ombrófila Mista ocorre nas porções planálticas do Estado, situada em média entre 800 e 1.200 metros de altitude, sendo influenciada pelas baixas temperaturas e ocorrência de geadas no inverno, com marcada relevância fitofisionômica de elementos Coniferales e Laurales, com dominância de Araucaria angustifolia (RODERJAN et al., 2002). Os solos da área de estudo, segundo o mapa de solos do estado do Paraná (SANTOS et al., 2008), são classificados como associação entre Argissolo Vermelho-Amarelo distrófico e Cambissolo Háplico Tb distrófico. 


\section{Caracterização das áreas de amostragem}

Foram selecionadas duas áreas contíguas em processo de recuperação e com histórico antrópico distinto: Floresta Secundária Avançada (FSA) e Floresta Secundária Inicial (FSI). A vegetação da FSA tem aproximadamente 65 anos e se originou por regeneração natural, após extração seletiva de espécies nativas comerciais de alto valor agregado e práticas de agricultura com manejo de pousio.

Na FSI, houve desmatamento da vegetação e remoção das camadas superficiais do solo (A e B) na década de 60. Na década de 70, houve revegetação de parte da área degradada com a espécie Mimosa scabrella Benth (REICHMANN NETO; SOARES, 1983). Com o tempo, diversas outras espécies nativas foram sendo recrutadas e se estabeleceram nesse ambiente, aumentando a diversidade da vegetação.

Os diferentes processos de antropização a que as áreas foram submetidas se refletem também nas características do solo. Na FSI, devido à retirada das camadas superficiais, o solo se encontra desestruturado, e, apesar de a vegetação existente na área ter propiciado o desenvolvimento de um horizonte, a incipiente, o horizonte $\mathrm{C}$ permanece na camada superior em alguns pontos. Na FSA não houve retirada de solos da camada superficial, e a estrutura do solo não foi alterada.

\section{Amostragem da vegetação}

A vegetação foi avaliada por meio da amostragem de 10 parcelas de 10 x $15 \mathrm{~m}\left(150 \mathrm{~m}^{2}\right)$, distribuídas sistematicamente em cada uma das áreas. O número de parcelas se deve à pequena área da FSI, sendo que as parcelas foram alocadas de forma sistemática de forma a cobrir toda a extensão do fragmento. Apesar de a área da FSA ser maior, optou-se pelo mesmo número de parcelas que na FSI, para facilitar a comparação entre áreas quanto aos parâmetros da vegetação.

Nas parcelas, foram amostrados todos os indivíduos arbóreos com circunferência a altura do peito (CAP) igual ou superior a $15 \mathrm{~cm}$, incluindo as árvores mortas. As espécies não identificadas no campo foram coletadas e identificadas com auxílio de literatura e com consulta de exsicatas tombadas no Herbário da Universidade Federal do Paraná, no Herbário das Faculdades Integradas Espírita e no Museu Botânico Municipal de Curitiba - Paraná. A nomenclatura botânica foi conferida com o banco eletrônico de dados da Lista de Espécies da Flora do Brasil (JARDIM BOTÂNICO DO RIO DE JANEIRO, 2016).

\section{Análise dos dados}

A partir da análise da composição florística, foram calculados os índices de diversidade Shannon (H'), o índice de equabilidade de Pielou e o índice de dominância de Simpson.

$$
H^{\prime}=-\sum \dot{p} \times \mathrm{h} \dot{p}
$$

Em que:

$\mathrm{H}^{\prime}=$ índice de Diversidade de Shannon-Weaver;

pi = estimativa da proporção de indivíduos (i) encontrados em cada espécie, $\mathrm{pi}=\mathrm{ni} / \mathrm{N}$;

ni = número de indivíduos da espécie i;

$\mathrm{N}$ = número total de indivíduos amostrados;

$\ln =$ logaritmo neperiano.

$$
J=\frac{H^{\prime}}{\mathrm{h} S}
$$

Em que:

$\mathrm{J}=$ índice de Pielou;

$\mathrm{H}^{\prime}=$ índice de Shannon-Weaver;

$\mathrm{S}=$ número de espécies presentes. 


$$
C=1-\frac{\sum_{i=1}^{S} n_{i}\left(n_{i}-1\right)}{N(N-1)}
$$

Em que:

$1=$ é a medida de dominância

$\mathrm{C}=$ índice de dominância de Simpson;

ni = número de indivíduos amostrados da i-ésima espécie;

$\mathrm{N}$ = número total de indivíduos amostrados;

$\mathrm{S}=$ número de espécies amostradas.

Para comparação das áreas, foi realizada a análise de cluster, sendo utilizada uma matriz de abundância para calcular a matriz de similaridade com o índice de Bray-Curtis e o método de ligação com algoritmo Unweighted Pair Group Method with arithmetic (UPMGA). As espécies foram classificadas quanto aos grupos ecológicos como pioneiras e não pioneiras, quanto ao modo de dispersão dos propágulos e quanto à tolerância à sombra, conforme literatura (BACKES; IRGANG, 2002; CARVALHO, 2006; LORENZI, 2008).

A curva média de acumulação de espécies com incremento do número de indivíduos amostrados foi calculada no programa EstimateS 8.2.0 (COLWELL, 2009), considerando 100 aleatorizações dos dados. Além da curva média, foi calculado o número esperado de espécies utilizando o estimador de riqueza não paramétrico Bootstrap, estimador de riqueza baseado na incidência de espécies, permitindo padronizar as comparações de riqueza de espécies a um número comum de indivíduos (FREITAS; MAGALHÃES, 2012).

Para caracterização da estrutura horizontal das áreas, foram calculados os estimadores fitossociológicos absolutos e relativos de densidade, dominância e frequência, além dos valores de cobertura (VC) e valor de importância (VI), conforme Mueller-Dombois e Ellenberg (1974).

A estrutura diamétrica das áreas foi caracterizada por meio das frequências do número de árvores para classes de diâmetro com amplitude de $5 \mathrm{~cm}$. Os parâmetros fitossociológicos e o dendrograma foram calculados no programa FITOPAC 2.1 (SHEPERD, 2009) e os parâmetros da estrutura diamétrica foram calculados no Excel 2010.

\section{RESULTADOS E DISCUSSÃO}

\section{Análise florística}

A curva média de acumulação de espécies nas duas áreas (Figura 2) mostra que na FSA houve maior taxa de acumulação, pois foram amostradas 58 espécies nessa área, em comparação às 41 espécies amostradas na FSI, mesmo que o número de indivíduos amostrados na FSA tenha sido menor quando comparado à FSI. Quanto ao número esperado de espécies calculado pelo estimador Bootstrap, na FSI foram estimadas 46 espécies, enquanto na FSA foram estimadas 67 espécies, o que representa que cerca de $90 \%$ e $87 \%$ das espécies foram efetivamente amostradas nas duas áreas, respectivamente. 

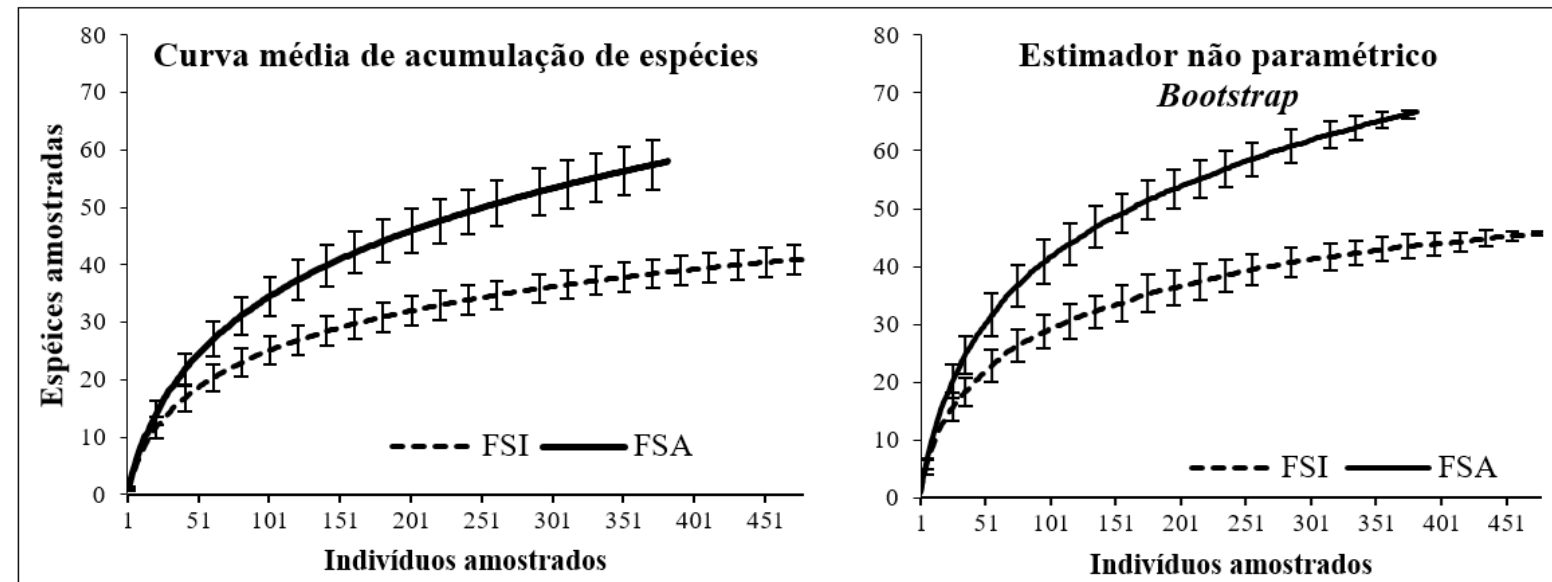

FIGURA 2: Curva média de acumulação de espécies e número de espécies estimado pelo método não paramétrico Bootstrap em duas áreas em processo de recuperação em Bocaiúva do Sul-PR.

FIGURE 2: Mean curve of accumulation of species and estimated number of species by non-parametric method Bootstrap in two areas under environmental recovery process in Bocaiúva do Sul, PR state.

Apesar de a curva média de acumulação de espécies não ter estabilizado, considera-se que a amostragem foi significativa, uma vez que abrangeu grande parte das espécies esperadas para a área. Além disso, para florestas tropicais é praticamente impossível atingir a estabilidade da curva média de acumulação de espécies por meio de amostragem. Isto porque a assíntota da curva de acúmulo de espécies só é atingida se a distribuição espacial das espécies for aleatória, o que não acontece nas florestas naturais, nas quais a agregação é uma característica intrínseca (SCHILLING; BATISTA; COUTO, 2012).

Nas duas áreas pesquisadas, foram encontradas 97 espécies, pertencentes a 50 famílias botânicas. Na FSI, foram amostradas 40 espécies pertencentes a 24 famílias, enquanto na FSA foram amostradas 57 espécies pertencentes a 27 famílias (Tabela 1). Com exceção das espécies Hovenia dulcis e Pinus elliottii, as demais espécies amostradas nas áreas são de origem nativa.

TABELA 1: Lista florística e as características ecológicas de espécies identificadas em duas áreas em processo de recuperação em Bocaiúva do Sul-PR.

TABLE 1: List floristic and ecological characteristics of species identified in two areas under environmental recovery process in Bocaiúva do Sul, PR state.

\begin{tabular}{|c|c|c|c|c|c|c|c|}
\hline Família Botânica & Nome Científico & Nome Popular & $\mathrm{SD}$ & GE & GR & FSI & FSA \\
\hline Anacardiaceae & Schinus terebinthifolius Raddi & $\begin{array}{l}\text { Aroeira- } \\
\text { vermelha }\end{array}$ & $\mathrm{ZO}$ & $\mathrm{P}$ & $\mathrm{I}$ & 13 & 44 \\
\hline Annonaceae & Guatteria australis A.St.-Hil. & Pindaíba & $\mathrm{ZO}$ & NP & $\mathrm{T}$ & 3 & - \\
\hline \multirow[t]{3}{*}{ Aquifoliaceae } & Ilex brevicuspis Reissek & Voadeira & $\mathrm{ZO}$ & NP & $\mathrm{T}$ & 1 & - \\
\hline & Ilex microdonta Reissek & Caúna & $\mathrm{ZO}$ & NP & $\mathrm{T}$ & 2 & - \\
\hline & Ilex theezans Mart. ex Reissek & Orelha-de-mico & $\mathrm{ZO}$ & NP & $\mathrm{T}$ & 1 & - \\
\hline Araucariaceae & $\begin{array}{l}\text { Araucaria angustifolia (Bertol.) } \\
\text { Kuntze }\end{array}$ & $\begin{array}{l}\text { Pinheiro-do- } \\
\text { Paraná }\end{array}$ & $\mathrm{ZO}$ & $\mathrm{P}$ & $\mathrm{I}$ & 1 & - \\
\hline
\end{tabular}


TABELA 1: Continuação...

TABLE 1: Continued..

\begin{tabular}{|c|c|c|c|c|c|c|c|}
\hline Família Botânica & Nome Científico & Nome Popular & $\mathrm{SD}$ & GE & GR & FSI & FSA \\
\hline \multirow[t]{2}{*}{ Arecaceae } & Geonoma schottiana Mart. & Guaricana & $\mathrm{ZO}$ & NP & $\mathrm{T}$ & 4 & 1 \\
\hline & $\begin{array}{l}\text { Syagrus romanzoffiana (Cham.) } \\
\text { Glassman }\end{array}$ & Jerivá & $\mathrm{ZO}$ & $\mathrm{P}$ & $\mathrm{I}$ & 2 & 3 \\
\hline \multirow[t]{5}{*}{ Asteraceae } & Baccharis calvescens DC & $\begin{array}{l}\text { Alecrim-do- } \\
\text { mato }\end{array}$ & $\mathrm{AN}$ & $\mathrm{P}$ & I & - & 2 \\
\hline & Baccharis oreophila Malme & Vassoura & $\mathrm{AN}$ & $\mathrm{P}$ & $\mathrm{I}$ & 96 & 16 \\
\hline & $\begin{array}{l}\text { Piptocarpha angustifolia Dusén } \\
\text { ex Malme }\end{array}$ & $\begin{array}{l}\text { Vassourão- } \\
\text { branco }\end{array}$ & $\mathrm{AN}$ & $\mathrm{P}$ & I & 9 & 1 \\
\hline & $\begin{array}{l}\text { Piptocarpha axillaris (Less.) } \\
\text { Baker }\end{array}$ & $\begin{array}{l}\text { Vassourão- } \\
\text { cambará }\end{array}$ & $\mathrm{AN}$ & $\mathrm{P}$ & I & 10 & 3 \\
\hline & $\begin{array}{l}\text { Vernonanthura discolor (Spreng.) } \\
\text { H.Rob. }\end{array}$ & Vassourão-preto & $\mathrm{AN}$ & $\mathrm{P}$ & I & 11 & 1 \\
\hline Celastraceae & Maytenus gonoclada Mart. & Maytenus & $\mathrm{ZO}$ & NP & $\mathrm{T}$ & 7 & 1 \\
\hline Clethraceae & Clethra scabra Pers. & Carne-de-vaca & $\mathrm{AN}$ & $\mathrm{P}$ & $\mathrm{I}$ & 34 & 47 \\
\hline Cunoniaceae & Lamanonia ternata Vell. & Guaraperê & AN & $\mathrm{P}$ & $\mathrm{I}$ & - & 6 \\
\hline Cyatheaceae & Cyathea phalerata Mart. & $\begin{array}{l}\text { Xaxim- } \\
\text { espinhento }\end{array}$ & AN & NP & $\mathrm{T}$ & 38 & 13 \\
\hline \multirow[t]{2}{*}{ Euphorbiaceae } & $\begin{array}{l}\text { Alchornea triplinervia (Spreng.) } \\
\text { Müll.Arg. }\end{array}$ & Tapiá & $\mathrm{ZO}$ & NP & I & 2 & 3 \\
\hline & Tetrorchidium rubrivenium Poepp. & Canemaçu & $\mathrm{ZO}$ & $\mathrm{P}$ & $\mathrm{I}$ & - & 1 \\
\hline \multirow[t]{7}{*}{ Fabaceae } & Ateleia glazioveana Baill. & Timbó & $\mathrm{AN}$ & $\mathrm{P}$ & $\mathrm{I}$ & - & 1 \\
\hline & $\begin{array}{l}\text { Dahlstedtia floribunda (Vogel) } \\
\text { M.J. Silva \& A.M.G. Azevedo }\end{array}$ & $\begin{array}{l}\text { Embira-de-sapo- } \\
\text { timbó }\end{array}$ & $\mathrm{ZO}$ & NP & $\mathrm{T}$ & - & 2 \\
\hline & Dalbergia brasiliensis Vogel & Jacarandá & $\mathrm{AN}$ & NP & $\mathrm{I}$ & - & 1 \\
\hline & $\begin{array}{l}\text { Machaerium paraguariense } \\
\text { Hassl. }\end{array}$ & Cateretê & AN & NP & I & - & 2 \\
\hline & Machaerium stipitatum Vogel & Farinha-seca & $\mathrm{AN}$ & NP & $\mathrm{I}$ & - & 14 \\
\hline & Mimosa scabrella Benth. & Bracatinga & $\mathrm{AN}$ & $\mathrm{P}$ & $\mathrm{I}$ & 9 & 3 \\
\hline & $\begin{array}{l}\text { Senna multijuga (Rich.) H.S.Irwin } \\
\text { \& Barneby }\end{array}$ & Chuva-de-ouro & $\mathrm{AU}$ & $\mathrm{P}$ & $\mathrm{I}$ & 2 & 5 \\
\hline \multirow[t]{2}{*}{ Lamiaceae } & $\begin{array}{l}\text { Aegiphila integrifolia (Jacq.) } \\
\text { Moldenke }\end{array}$ & Pau-gaiola & $\mathrm{ZO}$ & $\mathrm{P}$ & I & 3 & - \\
\hline & $\begin{array}{l}\text { Vitex megapotamica (Spreng.) } \\
\text { Moldenke }\end{array}$ & Tarumã & $\mathrm{ZO}$ & NP & I & - & 3 \\
\hline \multirow[t]{2}{*}{ Lauraceae } & $\begin{array}{l}\text { Cinnamomum glaziovii (Mez) } \\
\text { Kosterm. }\end{array}$ & Canela-crespa & $\mathrm{ZO}$ & NP & $\mathrm{T}$ & 1 & - \\
\hline & Cryptocarya aschersoniana $\mathrm{Mez}$ & Canela-fogo & $\mathrm{ZO}$ & NP & $\mathrm{I}$ & 1 & - \\
\hline
\end{tabular}


TABELA 1: Continuação...

TABLE 1: Continued..

\begin{tabular}{|c|c|c|c|c|c|c|c|}
\hline Família Botânica & Nome Científico & Nome Popular & SD & GE & GR & FSI & FSA \\
\hline \multirow[t]{5}{*}{ Lauraceae } & Nectandra lanceolata Nees & Canela-amarela & $\mathrm{ZO}$ & $\mathrm{NP}$ & $\mathrm{T}$ & 4 & 5 \\
\hline & $\begin{array}{l}\text { Nectandra megapotamica } \\
\text { (Spreng.) Mez }\end{array}$ & Canelinha & $\mathrm{ZO}$ & NP & $\mathrm{T}$ & - & 1 \\
\hline & Nectandra oppositifolia Nees & $\begin{array}{l}\text { Canela- } \\
\text { ferrugem }\end{array}$ & $\mathrm{ZO}$ & NP & $\mathrm{T}$ & 2 & - \\
\hline & Ocotea puberula (Rich.) Nees & Canela-guaicá & $\mathrm{ZO}$ & NP & $\mathrm{T}$ & 3 & 5 \\
\hline & Persea major (Meisn.) L.E.Kopp & Pau-de-andrade & $\mathrm{ZO}$ & NP & $\mathrm{I}$ & - & 2 \\
\hline Laxmanniaceae & $\begin{array}{l}\text { Cordyline spectabilis Kunth \& } \\
\text { Bouché }\end{array}$ & Varaneira & $\mathrm{ZO}$ & NP & $\mathrm{T}$ & 1 & 25 \\
\hline \multirow[t]{2}{*}{ Melastomataceae } & Miconia sellowiana Naudin & Pixirica & $\mathrm{ZO}$ & $\mathrm{P}$ & I & 6 & 14 \\
\hline & Tibouchina sellowiana Cogn. & Quaresmeira & AN & $\mathrm{P}$ & I & 22 & 1 \\
\hline Meliaceae & Cedrela fissilis Vell. & Cedro & AN & $\mathrm{NP}$ & $\mathrm{I}$ & - & 1 \\
\hline \multirow[t]{8}{*}{ Myrtaceae } & $\begin{array}{l}\text { Blepharocalyx salicifolius (Kunth) } \\
\text { O.Berg }\end{array}$ & Murta & $\mathrm{ZO}$ & NP & $\mathrm{T}$ & - & 1 \\
\hline & $\begin{array}{l}\text { Campomanesia xanthocarpa } \\
\text { (Mart.) O.Berg }\end{array}$ & Guabiroba & $\mathrm{ZO}$ & NP & $\mathrm{T}$ & - & 1 \\
\hline & Eugenia neoverrucosa Sobral & Guamirim & $\mathrm{ZO}$ & NP & $\mathrm{T}$ & - & 2 \\
\hline & Eugenia uniflora $\mathrm{L}$. & Pitangueira & $\mathrm{ZO}$ & $\mathrm{NP}$ & $\mathrm{T}$ & - & 1 \\
\hline & Myrcia hatschbachii D.Legrand & $\begin{array}{l}\text { Caingá- } \\
\text { verdadeiro }\end{array}$ & $\mathrm{ZO}$ & NP & I & - & 8 \\
\hline & Myrcia sp. & Guamirim & $\mathrm{ZO}$ & NP & I & 1 & - \\
\hline & Myrcia splendens (Sw.) DC. & Guamirim & $\mathrm{ZO}$ & NP & $\mathrm{I}$ & 63 & 10 \\
\hline & Psidium cattleianum Sabine & Araçá & $\mathrm{ZO}$ & NP & $\mathrm{I}$ & - & 1 \\
\hline Pinaceae & Pinus elliottii L. & Pinus & AN & $\mathrm{P}$ & $\mathrm{I}$ & 8 & 2 \\
\hline \multirow[t]{3}{*}{ Primulaceae } & $\begin{array}{l}\text { Myrsine coriacea (Sw.) R.Br. ex } \\
\text { Roem. \& Schult. }\end{array}$ & Capororoquinha & $\mathrm{ZO}$ & $\mathrm{P}$ & I & 17 & 8 \\
\hline & $\begin{array}{l}\text { Myrsine laetevirens }(\mathrm{Mez}) \\
\text { Arechav. }\end{array}$ & Capororoca & $\mathrm{ZO}$ & NP & I & - & 1 \\
\hline & Myrsine umbellata Mart. & Capororocão & $\mathrm{ZO}$ & NP & $\mathrm{I}$ & 19 & 13 \\
\hline Rhamnaceae & Hovenia dulcis Thunb. & Uva-do-japão & $\mathrm{ZO}$ & $\mathrm{P}$ & $\mathrm{I}$ & - & 1 \\
\hline Rosaceae & Prunus myrtifolia (L.) Urb. & $\begin{array}{l}\text { Pessegueiro- } \\
\text { bravo }\end{array}$ & $\mathrm{ZO}$ & NP & I & - & 13 \\
\hline Rubiaceae & Psychotria vellosiana Benth. & Café-do-mato & $\mathrm{ZO}$ & NP & $\mathrm{I}$ & 1 & 10 \\
\hline Rutaceae & Zanthoxylum rhoifolium Lam. & Juvevê & $\mathrm{ZO}$ & NP & $\mathrm{I}$ & 1 & 15 \\
\hline \multirow[t]{2}{*}{ Salicaceae } & $\begin{array}{l}\text { Banara parviflora (A.Gray) } \\
\text { Benth. }\end{array}$ & Farinha-seca & $\mathrm{ZO}$ & NP & I & - & 1 \\
\hline & Casearia lasiophylla Eichler & $\begin{array}{l}\text { Guaçatunga- } \\
\text { graúda }\end{array}$ & $\mathrm{ZO}$ & NP & I & 4 & 7 \\
\hline
\end{tabular}


TABELA 1: Continuação...

TABLE 1: Continued...

\begin{tabular}{|c|c|c|c|c|c|c|c|}
\hline Família Botânica & Nome Científico & Nome Popular & SD & GE & GR & FSI & FSA \\
\hline \multirow[t]{2}{*}{ Salicaceae } & Casearia sylvestris $\mathrm{Sw}$. & $\begin{array}{l}\text { Guaçatunga- } \\
\text { preta }\end{array}$ & $\mathrm{ZO}$ & NP & I & 13 & 5 \\
\hline & Xylosma ciliatifolia (Clos) Eichler & Sucará & $\mathrm{ZO}$ & NP & I & 1 & - \\
\hline Sapindaceae & $\begin{array}{l}\text { Allophylus edulis (A.St.-Hil. et } \\
\text { al.) Hieron. ex Niederl. }\end{array}$ & Vacum & $\mathrm{ZO}$ & NP & $\mathrm{T}$ & - & 9 \\
\hline \multirow[t]{3}{*}{ Sapindaceae } & Allophylus petiolulatus Radlk. & $\begin{array}{l}\text { Vacum-folha- } \\
\text { larga }\end{array}$ & $\mathrm{ZO}$ & NP & $\mathrm{T}$ & - & 1 \\
\hline & Cupania vernalis Cambess. & Cuvatã & $\mathrm{ZO}$ & NP & I & - & 6 \\
\hline & Matayba elaeagnoides Radlk. & Miguel-pintado & $\mathrm{ZO}$ & NP & I & - & 26 \\
\hline Sapotaceae & $\begin{array}{l}\text { Chrysophyllum cf. marginatum } \\
\text { (Hook. \& Arn.) Radlk. }\end{array}$ & Aguaí-vermelho & $\mathrm{ZO}$ & $\mathrm{P}$ & I & - & 3 \\
\hline \multirow[t]{3}{*}{ Solanaceae } & Solanum mauritianum Scop. & Fumo-bravo & $\mathrm{ZO}$ & $\mathrm{P}$ & I & - & 1 \\
\hline & $\begin{array}{l}\text { Solanum sanctae-catharinae } \\
\text { Dunal }\end{array}$ & Canema & $\mathrm{ZO}$ & $\mathrm{P}$ & I & - & 1 \\
\hline & $\begin{array}{l}\text { Solanum swartzianum Roem. \& } \\
\text { Schult. }\end{array}$ & Fumeirinho & $\mathrm{ZO}$ & NP & I & 2 & 2 \\
\hline \multirow[t]{2}{*}{ Symplocaceae } & $\begin{array}{l}\text { Symplocos pentandra (Mattos) } \\
\text { Occhioni ex Aranha }\end{array}$ & Sete-sangrias & $\mathrm{ZO}$ & NP & I & 10 & - \\
\hline & Symplocos tenuifolia Brand & Maria-mole & $\mathrm{ZO}$ & NP & I & 3 & 6 \\
\hline
\end{tabular}

Em que: FSI = Floresta Secundária Inicial; FSA = Floresta Secundária Avançada; $\mathrm{SD}=$ Síndrome de dispersão; GE $=$ Grupo Ecológico; $\mathrm{GR}=$ Guilda de Regeneração; $\mathrm{ZO}$ = dispersão zoocórica; $\mathrm{AN}$ = dispersão anemocórica; $\mathrm{AU}=$ dispersão autocórica; $\mathrm{P}=$ espécie pioneira; $\mathrm{NP}=$ espécie não pioneira; $\mathrm{T}=$ tolerante à sombra; $\mathrm{I}=$ intolerante à sombra.

O número de espécies encontradas é significativo e representa bem a alta riqueza de espécies na região (diversidade beta). As famílias com as maiores riquezas específicas na FSI são típicas de áreas abertas e estágios iniciais, e a família Lauraceae se destacou das demais quanto ao número de espécies (6), seguida por Asteraceae (4), Aquifoliaceae e Salicaceae (3).

A família Asteraceae se destaca também quanto ao número de indivíduos, devido principalmente à grande densidade de Baccharis oreophila. A presença de espécies do gênero Baccharis, com grande participação da estrutura da florestal, indica a ocorrência de distúrbios antrópicos recentes na área. Heiden et al. (2007) citam que esse gênero é frequente em áreas degradadas em processo de regeneração.

Na FSA, as famílias Fabaceae e Myrtaceae se destacaram quanto ao número de espécies (7), seguidas por Asteraceae (5), Lauraceae e Sapindaceae (4), Primulaceae, Salicaceae e Solanaceae (3). Quanto ao número de indivíduos, destacam-se as famílias Clethraceae, Anacardiaceae e Sapindaceae. Algumas espécies, especialmente não pioneiras, somente foram amostradas na FSA, o que demonstra que há diferença entre as áreas quanto ao processo de recuperação, sendo que, apesar da FSI apresentar uma composição florística bem diversa, ainda não se equipara à FSA. Além disso, a Araucaria angustifolia, apesar de ser um elemento característico na composição florística da Floresta Ombrófila Mista, não se apresentou como uma espécie dominante, sendo amostrada apenas na FSI. Isso demonstra que essa espécie sofreu exploração no passado, o que prejudicou sua regeneração natural.

Considerando que a área de estudo se encontra em um ecótono, as famílias e espécies encontradas 
neste estudo configuram um padrão florístico para Floresta Ombrófila Mista, sendo muitas dessas famílias as mais representativas em área de conservação e preservação (KLAUBERG et al., 2010; HIGUCHI et al., 2012; SANTOS et al., 2012; PSCHEIDT et al., 2015) e em remanescentes antropizados (SILVA et al., 2012; HIGUCHI et al., 2013; FIORENTIN et al., 2015; FERREIRA et al., 2016).

Quanto à síndrome de dispersão, na FSI 22,5\% das espécies e 55\% dos indivíduos são anemocóricos, $2,5 \%$ das espécies e $0,5 \%$ dos indivíduos autocóricos, enquanto $75 \%$ das espécies e $44,5 \%$ dos indivíduos zoocóricos. Na FSA, $28,1 \%$ das espécies e $29,8 \%$ dos indivíduos anemocóricos, $1,8 \%$ das espécies e 1,3\% dos indivíduos autocóricos e 70,2\% das espécies e $68,8 \%$ dos indivíduos possuem dispersão zoocórica. A maior proporção de indivíduos com dispersão zoocórica também foi encontrada por Liebsch et al. (2009) em Floresta Ombrófila Mista, no Paraná. Destaca-se ainda a anemocoria como síndrome de dispersão de todas as espécies de Asteraceae amostradas em ambas as áreas, o que confere a essa família extrema importância na recuperação de áreas degradadas, participando tanto como pioneiras na colonização de ambientes degradados quanto na ocorrência em clareiras e bordas de mata (HEIDEN et al., 2007).

$\mathrm{O}$ valor dos índices de diversidade das áreas (Tabela 2) mostra que na FSA a vegetação é mais diversa que na FSI. O Índice de Shannon-Wiener encontrado para FSA $\left(\mathrm{H}^{\prime}=3,39\right.$ nats.indivíduo $\left.{ }^{-1}\right)$ e FSI $\left(\mathrm{H}^{\prime}=2,89\right.$ nats.indivíduo $\left.{ }^{-1}\right)$ indicou uma heterogeneidade superior e semelhante, respectivamente, quando comparado com outros trabalhos em fragmentos de Floresta Ombrófila Mista (NEGRINI et al., 2012; SOUZA et al., 2014).

TABELA 2: Índices de diversidade da vegetação amostrada em duas áreas de floresta secundária em Bocaiúva do Sul-PR.

TABLE 2: Diversity indices of vegetation sampled in two areas of secondary forest in Bocaiúva do Sul, PR state.

\begin{tabular}{cccc}
\hline Área & Índice de Shannon-Wiener & Índice de Pielou & Índice de Simpson \\
\hline FSI & 2.890 & 0,778 & 0,087 \\
\hline FSA & 3.385 & 0,834 & 0,050 \\
\hline
\end{tabular}

Em que: FSI = Floresta Secundária Inicial; FSA = Floresta Secundária Avançada.

A análise de cluster da similaridade florística das duas áreas (Figura 3) permitiu a diferenciação de dois agrupamentos, sendo o primeiro formado pela maioria das parcelas da FSA, enquanto o segundo foi formado pelas parcelas da FSI, além de duas parcelas da FSA implantadas na área limítrofe com a FSI. Dessa forma, percebe-se que as parcelas mais próximas estão mais relacionadas entre si que as distantes, apresentando maior valor de similaridade florística do que as parcelas mais distantes.

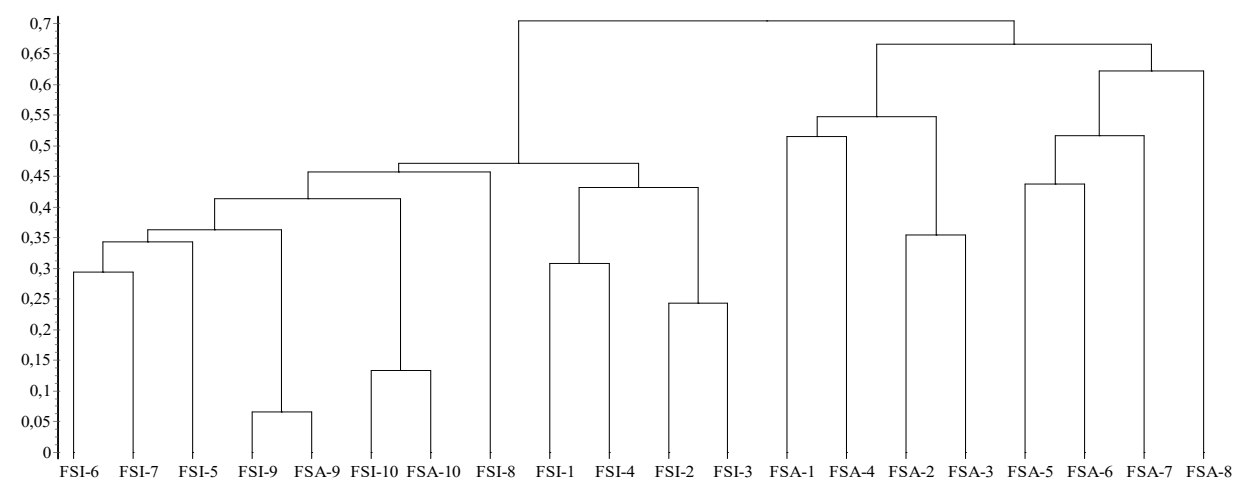

FIGURA 3: Dendrograma de similaridade florística (Índice de Bray-Curtis) entre as parcelas amostradas em duas áreas de floresta secundária em Bocaiúva do Sul-PR.

FIGURE 3: Dendrogram of floristic similarity (Bray-Curtis Index) between sampled plots in two areas under environmental recovery process in Bocaiúva do Sul, PR state. 


\section{Análise da estrutura horizontal}

Os parâmetros estruturais da vegetação amostrada nas duas áreas (Tabela 3) evidenciam que não há diferença significativa quanto ao número de espécies e de famílias botânicas amostradas por parcela, o que reforça o fato de que, do ponto de vista florístico, as áreas são semelhantes. Também não houve diferença entre as áreas em relação ao número de indivíduos ramificados.

Por outro lado, as áreas apresentaram diferenças no que tange aos demais parâmetros estruturais, sendo que, na FSA, os valores da área basal, volume total, altura média e CAP médio foram superiores à FSI. O número de indivíduos arbóreos e arborescentes foi superior na FSI, o que se deve, provavelmente, à maior abertura do dossel nessa área, que permite o estabelecimento de maior número de indivíduos de menor porte, como pode ser verificado pelo menor CAP médio e altura dos indivíduos nessa área.

Esses resultados indicam uma cobertura vegetal bastante expressiva, após 35 e 65 anos, respectivamente, das últimas intervenções nos dois locais. A maior área basal em estágios sucessionais mais avançados é comum em ambientes florestais, enquanto a densidade nem sempre segue essa tendência. A densidade menor da FSA em comparação com a área FSI é resultado de um ambiente estratificado verticalmente, no qual as árvores de maior porte competem com as menores e inibem o seu desenvolvimento. Dessa forma, enfatiza-se que a FSI apresentou uma densidade maior em função de estar em um estágio sucessional mais inicial em comparação à FSA, na qual as espécies e indivíduos competem mais equitativamente entre si pelos recursos existentes.

TABELA 3: Parâmetros estruturais da vegetação amostrada em duas áreas de floresta secundária em Bocaiúva do Sul-PR.

TABLE 3: Structural parameters of vegetation sampled in two areas of secondary forest in Bocaiúva do Sul, PR state.

\begin{tabular}{cccccccccc}
\hline Área & $\begin{array}{c}\text { Famílias por } \\
\text { parcela }\end{array}$ & $\begin{array}{c}\text { Espécies por } \\
\text { parcela }\end{array}$ & $\begin{array}{c}\text { Indivíduos por } \\
\text { hectare }\end{array}$ & $\mathrm{G}$ & $\mathrm{V}$ & $\mathrm{H}_{\mathrm{tot}}$ & $\mathrm{CAP}_{\text {eq }}$ Ramificações \\
& & & & & & & & \\
$\left(\mathrm{m}^{2} \mathrm{ha}^{-1}\right)$ & $\left(\mathrm{m}^{3} \mathrm{ha}^{-1}\right)$ & $(\mathrm{m})$ & $(\mathrm{cm})$ & $(\%)$ \\
\hline FSI & 12 & $16^{\text {ns }}$ & $3180^{*}$ & 25,58 & 178,72 & 7,36 & 29,46 & 1,51 \\
\hline FSA & $13 \mathrm{~ns}$ & 16 & 2547 & $35,13^{*}$ & $342,12^{*}$ & $9,15^{*}$ & $35,97^{*}$ & $2,03^{\text {ns }}$ \\
\hline
\end{tabular}

Em que: FSI = Floresta Secundária Inicial; FSA = Floresta Secundária Avançada; G = área basal; V = volume total; $\mathrm{H}_{\text {tot }}=$ altura total; $\mathrm{CAP}_{\mathrm{eq}}=$ circunferência à altura do peito (CAP) equivalente. *Estatisticamente superior pelo teste $\mathrm{T}$, a $95 \%$ de probabilidade; ${ }^{\text {ns }}$ Diferença não significativa.

As espécies mais importantes na estrutura da FSI (Tabela 4) são predominantemente espécies pioneiras, comuns em áreas em estágio inicial de sucessão secundária. Considerando o valor de importância, as principais espécies foram Baccharis oreophila (17,0\%), Myrcia splendens (8,8 \%), Cyathea phalerata (7,4 \%) e Clethra scabra (6,4\%), Myrsine umbellata (4,4\%), Tibouchina sellowiana (4,1\%), Mimosa scabrella (3,9\%), Myrsine ferruginea (3,5\%) e Piptocarpha angustifolia (3,2\%). A espécie Baccharis oreophila apresentou os maiores valores de importância e cobertura na FSI, o que indica que a área está em estágio inicial de sucessão secundária, em processo de regeneração (HEIDEN et al., 2007). Plantas do gênero Baccharis spp. são arbustivas, de porte médio e pioneiras que apresentam produção alta de biomassa (REIS; ZAMBONIN; NAKAZONO, 1999), melhorando inicialmente as condições do solo para o estabelecimento de espécies arbóreas definitivas (IMAGUIRE, 1980). 
TABELA 4: Parâmetros fitossociológicos para as dez espécies com maior valor de importância em duas áreas de floresta secundária em Bocaiúva do Sul-PR.

TABLE 4: Phytosociology parameters of ten species with the highest importance value in two areas of secondary forest in Bocaiúva do Sul, PR state.

\begin{tabular}{ccccccccc}
\hline Espécies & DA & DR & FA & FR & DoA & DoR & VI & VC \\
& $\left(\right.$ ind. ha $\left.{ }^{-1}\right)$ & $(\%)$ & $(\%)$ & $(\%)$ & $\left(\mathrm{m}^{2} \mathrm{ha}^{-1}\right)$ & $(\%)$ & $(\%)$ & $(\%)$ \\
\hline
\end{tabular}

Floresta Secundária Inicial

\begin{tabular}{lcccccccc}
\hline Baccharis oreophila Malme & 640 & 20,1 & 100,0 & 6,4 & 6,24 & 24,4 & 17,0 & 22,3 \\
\hline Myrcia splendens (Sw.) DC. & 420 & 13,2 & 100,0 & 6,4 & 1,73 & 6,8 & 8,8 & 10,0 \\
\hline Indivíduos mortos & 307 & 9,6 & 100,0 & 6,4 & 2,41 & 9,4 & 8,5 & 9,5 \\
\hline Cyathea phalerata Mart. & 253 & 8,0 & 90,0 & 5,7 & 2,17 & 8,5 & 7,4 & 8,2 \\
\hline Clethra scabra Pers. & 227 & 7,1 & 80,0 & 5,1 & 1,79 & 7,0 & 6,4 & 7,1 \\
\hline Myrsine umbellata Mart. & 127 & 4,0 & 60,0 & 3,8 & 1,41 & 5,5 & 4,4 & 4,8 \\
\hline Tibouchina sellowiana Cogn. & 147 & 4,6 & 70,0 & 4,5 & 0,80 & 3,1 & 4,1 & 3,9 \\
\hline Mimosa scabrella Benth. & 60 & 1,9 & 70,0 & 4,5 & 1,34 & 5,2 & 3,9 & 3,6 \\
\hline $\begin{array}{l}\text { Myrsine ferruginea } \text { (Ruiz \& } \\
\text { Pav.) Mez }\end{array}$ & 113 & 3,6 & 70,0 & 4,5 & 0,67 & 2,6 & 3,5 & 3,1 \\
\hline $\begin{array}{l}\text { Piptocarpha angustifolia } \text { Dusén } \\
\text { ex Malme }\end{array}$ & 60 & 1,9 & 60,0 & 3,8 & 0,97 & 3,8 & 3,2 & 2,8 \\
\hline $\begin{array}{l}\text { Outras (31 espécies) } \\
\text { TOTAL }\end{array}$ & 827 & 26,0 & 770,0 & 49,0 & 6,03 & 23,6 & 32,9 & 24,8 \\
\hline
\end{tabular}

Floresta Secundária Avançada

\begin{tabular}{lcccccccc}
\hline Schinus terebinthifolius Raddi & 293 & 11,5 & 90,0 & 5,7 & 5,94 & 16,9 & 11,4 & 14,2 \\
\hline Clethra scabra Pers. & 313 & 12,3 & 80,0 & 5,1 & 5,69 & 16,2 & 11,2 & 14,3 \\
\hline Matayba elaeagnoides Radlk. & 173 & 6,8 & 40,0 & 2,5 & 3,00 & 8,5 & 6,0 & 7,7 \\
\hline Indivíduos mortos & 133 & 5,2 & 90,0 & 5,7 & 2,31 & 6,6 & 5,8 & 5,9 \\
\hline $\begin{array}{l}\text { Cordyline spectabilis Kunth \& } \\
\text { Bouché }\end{array}$ & 167 & 6,5 & 60,0 & 3,8 & 0,70 & 2,0 & 4,1 & 4,3 \\
\hline Zanthoxylum rhoifolium Lam. & 100 & 3,9 & 30,0 & 1,9 & 1,41 & 4,0 & 3,3 & 4,0 \\
\hline Machaerium stipitatum Vogel & 93 & 3,7 & 50,0 & 3,2 & 1,00 & 2,8 & 3,2 & 3,3 \\
\hline Baccharis oreophila Malme & 107 & 4,2 & 20,0 & 1,3 & 1,35 & 3,8 & 3,1 & 4,0 \\
\hline Cyathea phalerata Mart. & 87 & 3,4 & 50,0 & 3,2 & 0,78 & 2,2 & 2,9 & 2,8 \\
\hline Myrcia splendens (Sw.) DC. & 67 & 2,6 & 60,0 & 3,8 & 0,64 & 1,8 & 2,8 & 2,2 \\
\hline Outras (48 espécies) & 1014 & 39,8 & 1000,0 & 63,7 & 12,30 & 35,0 & 46,2 & 37,4 \\
\hline \multicolumn{1}{c}{ TOTAL } & 2547 & 100 & 1570 & 100 & 35,12 & 100 & 100 & 100 \\
\hline
\end{tabular}

Em que: $\mathrm{DA}=$ densidade absoluta; $\mathrm{DR}=$ densidade relativa; $\mathrm{FA}=$ Frequência absoluta; $\mathrm{FR}=$ Frequência relativa; DoA

$=$ Dominância absoluta; DoR = Dominância relativa; $\mathrm{VI}=$ Valor de Importância; $\mathrm{VC}=$ Valor de Cobertura . 
Na FSA, Schinus terebinthifolius foi a espécie que apresentou o maior valor de importância, destacando-se como planta dominante no ambiente e encontrada entre o grupo de plantas dominantes (HÜLLER et al., 2011; SANTOS, 2014). Schinus terebinthifolius apresenta comportamento de espécie secundária, mantendo-se em ambientes com espécies já estabelecidas que promovem sombreamento com facilidade de adaptação aos ambientes com maior incidência de luz (CHIAMOLERA; ÂNGELO; BOEGER, 2011). Além de Schinus terebinthifolius, as espécies com maiores valores de importância foram Clethra scabra (11,2\%), Matayba elaeagnoides (6,0\%), Cordyline spectabilis (4,1\%), Zanthoxylum rhoifolium (3,3\%), Machaerium stipitatum (3,2\%), Baccharis oreophila (3,1\%), Cyathea phalerata (2,9\%) e Myrcia splendens $(2,8 \%)$.

Os indivíduos classificados como mortos apresentaram valor de importância de 8,5\% e 5,8\%, para a FSI e FSA, respectivamente, valores que podem ser considerados altos. O número de indivíduos mortos na FSI foi superior à FSA, o que indica a substituição das espécies pioneiras exigentes em luz por espécies secundárias tolerantes à sombra, característica do processo de sucessão secundária.

Além disso, a estrutura da vegetação na FSI, com maior densidade de indivíduos de menores diâmetros, favorece a maior mortalidade de indivíduos, uma vez que árvores menores e com menores diâmetros possuem maiores probabilidades de morrer (CASTRO et al., 2014) no processo de sucessão secundária. Rossi et al. (2007) salientam que, para florestas nativas inequiâneas, a probabilidade de mortalidade das árvores do dossel é sempre inferior à probabilidade dos indivíduos dominados serem suprimidos da estrutura da floresta.

Quanto à tendência da distribuição diamétrica (Figura 4), observa-se a forma do "J-invertido" dos histogramas, como é esperado em florestas heterogêneas, sendo que a FSA apresenta maior número de representantes nas classes de diâmetro maiores e menos indivíduos nas classes de diâmetro menores se comparada à FSI.

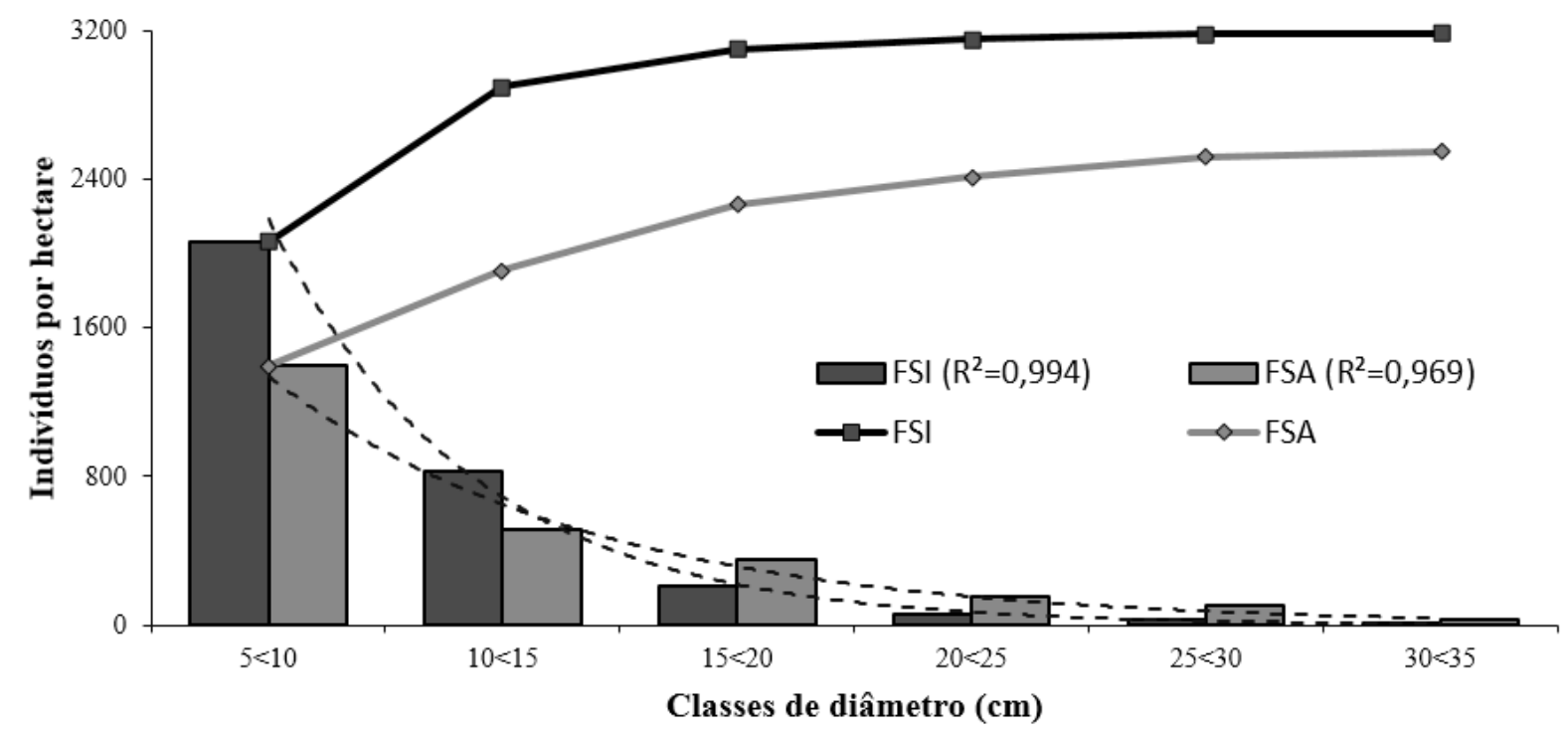

FIGURA 4: Frequência absoluta e acumulada da distribuição diamétrica $(\mathrm{cm})$ dos indivíduos amostrados em duas áreas de florestas secundárias em Bocaiúva do Sul-PR.

FIGURE 4: Absolute and cumulative frequency of diametric distribution $(\mathrm{cm})$ of the sampled individuals in two areas of secondary forest in Bocaiúva do Sul, PR state. 


\section{CONCLUSÃO}

A composição florística da comunidade arbórea da FSA se mostrou mais desenvolvida que na FSI, indicando que o grau de perturbação antrópico das áreas influenciou na composição de espécies. Na FSI, foram amostradas espécies predominantemente pioneiras, características de áreas abertas ou em estágio inicial de sucessão secundária, enquanto na FSA foi amostrado maior número de espécies não pioneiras, algumas características de áreas bem preservadas de Floresta Ombrófila Mista. Isso demonstra que a composição de espécies em ambas as áreas está de acordo com o seu estágio de sucessão secundária.

Quanto aos parâmetros estruturais, também houve diferenciação entre as áreas, sendo que na FSI há maior número de indivíduos de menor porte em comparação à FSA.

Este estudo sugere que o plantio monoespecífico com espécie pioneira com capacidade de fixação de nitrogênio pode ser suficiente para promover a sucessão secundária com a regeneração de espécies de diferentes grupos ecológicos e a recomposição florestal de áreas degradadas.

\section{AGRADECIMENTOS}

À UFPR, CAPES, CNPq, COPEL, LACTEC e ao projeto P\&D ANELL GEE-APINE pela infraestrutura de pesquisa, bolsas de estudo, pesquisa e recursos financeiros, ao Prof. Dr. Antonio Dunaski, da Faculdades Espíritas, e ao botânico Osmar dos Santos Ribas, do Museu Botânico Municipal de Curitiba, pelo auxílio na identificação das espécies.

\section{REFERÊNCIAS}

BACKES, P.; IRGANG, B. Árvores do Sul: guia de identificação e interesse ecológico. Santa Cruz do Sul: Instituto Souza Cruz, 2002. 326 p.

BARREIRA, S. et al. Estudo da estrutura da regeneração natural e da vegetação adulta de um Cerrado senso stricto para fins de manejo florestal. Scientia Forestalis, Piracicaba, v. 1, n. 61, p. 64-78, jun. 2002.

CARVALHO, P. E. R. Espécies arbóreas brasileiras. Brasília: Embrapa Informações Tecnológicas; Colombo: Embrapa Floresta, 2006. v. 2. 627 p.

CASTRO, R. et al. Competição em nível de árvore individual em uma Floresta Estacional Semidecidual. Silva Lusitana, Lisboa, v. 22, n. 1, p. 43-66, jun. 2014.

CHIAMOLERA, L. B.; ANGELO, A. C.; BOEGER, M. R. Crescimento e sobrevivência de quatro espécies florestais nativas plantadas em áreas com diferentes estágios de sucessão no reservatório Iraí-PR. Floresta, Curitiba, v. 41, n. 4, p. 765-778, out./dez. 2011.

COLWELL, R. K. EstimateS: Statistical estimation of species richness and shared species from samples. Version 8. 2. 0. [s. 1.: s. n.], 2009. Disponível em: <http://viceroy.eeb.uconn.edu/estimates/>. Acesso em: 06 mar. 2015.

DARONCO, C.; MELO, A. C. G.; DURIGAN, G. Ecossistema em restauração versus ecossistema de referência: estudo de caso da comunidade vegetal de mata ciliar em região de Cerrado, Assis, SP, Brasil. Hoehnea, São Paulo, v. 40, n. 3, p. 485-498, set. 2013.

FERREIRA, T. S. et al. Composição florístico-estrutural ao longo de um gradiente de borda em fragmento de Floresta Ombrófila Mista alto-montana em Santa Catarina. Ciência Florestal, Santa Maria, v. 26, n. 1, p. 123-134, jan./mar. 2016.

FIORENTIN, L. D. et al. Análise florística e padrão espacial da regeneração natural em área de Floresta Ombrófila Mista na região de Caçador, SC. Floresta Ambiente, Seropédica, v. 22, n. 1, p. 60-70, mar. 2015. FREITAS, W. K.; MAGALHÃES, L. M. S. Métodos e parâmetros para estudo da vegetação com ênfase no estrato arbóreo. Floresta e Ambiente, Seropédica, v. 19, n.4, p. 520-539, dez. 2012.

GUILHERME, F. A. G. Efeitos da cobertura de dossel na densidade e estatura de gramíneas e da regeneração natural de plantas lenhosas em mata de galeria, Brasília. Revista Cerne, Lavras, v. 6, n. 1, p. 60-66, 2000. HEIDEN, G. et al. Biogeografia de Baccharis sect. caulopterae (Asteraceae) no Rio Grande do Sul, Brasil. Rodriguésia, Rio de Janeiro, v. 58, n. 4, p. 787-796, out./dez. 2007.

HIGUCHI, P. et al. Florística e estrutura do componente arbóreo e análise ambiental de um fragmento 
de Floresta Ombrófila Mista Altomontana no município de Painel, SC. Ciência Florestal, Santa Maria, v. 23, n. 1, p. 153-164, jan./mar. 2013.

HIGUCHI, P. et al. Influência de variáveis ambientais sobre o padrão estrutural e florístico do componente arbóreo, em um fragmento de Floresta Ombrófila Mista Montana em Lages, SC. Ciência Florestal, Santa Maria, v. 22, n. 1, p. 79-90, jan./mar. 2012.

HÜLLER, A. et al. Estrutura fitossociológica da vegetação arbórea do parque natural municipal de Santo Ângelo, Santo Ângelo, RS. Ciência Florestal, Santa Maria, v. 21, n. 4, p. 629-639, out./dez. 2011.

IMAGUIRE, N. Contribuição ao estudo florístico e ecológico da Fazenda Experimental do Setor de Ciências Agrárias da Universidade Federal do Paraná. 2. O porquê da existência dos campos e matas no primeiro e segundo planaltos paranaenses. Acta Biológica Paranaense, Curitiba, v. 8. p. 47-72, dez. 1980.

IBGE. Manual técnico da vegetação brasileira. 2. ed. Rio de Janeiro: IBGE, 2012. 271 p.

INSTITUTO AGRONÔMICO DO PARANÁ. Cartas climáticas do Paraná. 2015. Disponível em: $<$ http://goo.gl/aMfXmY>. Acesso em: 08 de maio de 2015.

JARDIM BOTÂNICO DO RIO DE JANEIRO. Flora do Brasil, 2020 em construção. Rio de Janeiro: Jardim Botânico do Rio de Janeiro, 2016. Disponível em: <http://floradobrasil.jbrj.gov.br/>. Acesso em: set. 2016.

KAGEYAMA, P. Y.; CASTRO, C. F. A. Sucessão secundária, estrutura genética e plantações de espécies arbóreas nativas. IPEF, Piracicaba, n. 41/42, p. 83-93, jan./dez. 1989.

KAGEYAMA, P.; GANDARA, F. B. Restauração e conservação de ecossistemas tropicais. In: CULLEN, L. et al. Métodos de estudo em Biologia da Conservação e Manejo da Vida Silvestre. Curitiba: UFPR, 2006. p. 383-394.

KLAUBERG, C. et al. Florística e estrutura de um fragmento de Floresta Ombrófila Mista no Planalto Catarinense. Biotemas, Florianópolis, v. 23, n. 1, p. 35-47, jan. 2010.

LIEBSCH, D. et al. Levantamento florístico e síndromes de dispersão em remanescentes de Floresta Ombrófila Mista na região centro-sul do estado do PR. Hoehnea, São Paulo, v. 36, n. 2, p. 233-248, jun. 2009.

LORENZI, H. Árvores brasileiras: manual de identificação e cultivo de plantas arbóreas nativas do Brasil. Nova Odessa: Plantarum, 2008. 384 p.

MENDES, S. Comparação entre os estratos arbóreo e de regeneração da mata de galeria da Estação Ecológica do Panga, Uberlândia-MG. 2002. 77 f. Dissertação (Mestrado em Ecologia e Conservação de Recursos Naturais) - Universidade Federal de Uberlândia, Uberlândia, MG, 2002.

MIRANDA NETO, A. et al. Florística e estrutura do estrato arbustivo-arbóreo de uma floresta restaurada com 40 anos, Viçosa, MG. Árvore, Viçosa, MG, v. 36, n. 5, p. 869-878, set./out. 2012.

MUELLER-DOMBOIS, D.; ELLENBERG, H. Aims and methods of vegetation ecology. New York: Wiley \& Sons, 1974. 574 p.

NEGRINI, M. et al. Dispersão, distribuição espacial e estratificação vertical da comunidade arbórea em um fragmento florestal no planalto catarinense. Revista Árvore, Viçosa, MG, v. 36, n. 5, p. 919-929, set./out. 2012.

PSCHEIDT, F. et al. Variações florísticas-estruturais da comunidade arbórea associadas à distância da borda em um fragmento florestal no planalto sul-catarinense. Floresta, Curitiba, v. 45, n. 2, p. 421-430, abr./jun. 2015.

REICHMANN NETO, F.; SOARES, R. V. Recomposição vegetal com espécies florestais e rastejantes em "áreas de empréstimo" da Hidrelétrica Governador Parigot de Souza. Floresta, Curitiba, v. 14, n. 2, p. 4-14, dez. 1983.

REIS, A.; ZAMBONIN, R. M.; NAKAZONO, E. M. Recuperação de áreas florestais degradadas utilizando a sucessão e as interações planta-animal. São Paulo: Conselho Nacional da Reserva da Biosfera da Mata Atlântica, 1999. 43 p.

RODERJAN, C. V. et al. As unidades fitogeográficas do Estado do Paraná, Brasil. Ciência \& Ambiente, Santa Maria, v. 24, p. 75-92, jan./jun. 2002.

RODRIGUES, R. R. et al. On the restoration of high diversity forests: 30 years of experience in the Brazilian Atlantic Forest. Biological Conservation, Amsterdam, v. 142, p. 1242-1255, jan. 2009.

RODRIGUES, R. R. et al. Large-scale ecological restoration of high-diversity tropical in SE Brazil. 
Forest Ecology and Management, New South Wales, v. 261, n. 10, p. 1605-1613, maio 2011.

RODRIGUES, R. R.; GANDOLFI, S. Conceitos, tendências e ações para a recuperação de florestas ciliares. In: RODRIGUES, R. R.; LEITÃO FILHO, H. (Ed.). Matas ciliares: conservação e recuperação. São Paulo: EDUSP, 2004. p. 235-247.

ROSSI, L. M. B. et al. Modelagem de mortalidade em florestas naturais. Floresta, Curitiba, v. 37, n. 2, p. 275-291, maio/ago. 2007.

SANTOS, A. A. P. Avaliação florística e estrutural de uma Floresta Ombrófila Mista Montana urbana. 2014. 130 f. Dissertação (Mestrado em Engenharia Florestal) - Universidade Federal do Paraná, Curitiba, 2014.

SANTOS, C. S. et al. Levantamento florístico e fitossociológico de um fragmento florestal no município de Faxinal dos Guedes, SC. Unoesc \& Ciência, Joaçaba, v. 3, n. 1, p. 7-22, jan./jun. 2012.

SANTOS, H. G. et al. Distribuição e ocorrência dos solos no Estado do Paraná. In: BHERING, S. B.; SANTOS, H. G. Mapa de solos Estado do Paraná: legenda atualizada. Rio de Janeiro: Embrapa Solos; Colombo: Embrapa Florestas; Londrina: Instituto Agronômico do Paraná, 2008. p. 49-74.

SILVA, A. C. et al. Relações florísticas e fitossociologia de uma Floresta Ombrófila Mista Montana secundária em Lages, Santa Catarina. Ciência Florestal, Santa Maria, v. 22, n. 1, p. 193-206, jan./mar. 2012.

SILVA, W. C. et al. Estrutura horizontal e vertical do componente arbóreo em fase de regeneração natural na mata Santa Luzia, no município de Catende-PE. Revista Árvore, Viçosa, MG, v. 34, n. 5, p. 863-869, out. 2010.

SOUZA, K. et al. Análise fitossociológica de trilha ecológica em Floresta Ombrófila Mista. Revista de Ciências Agroveterinárias, Lages, v. 13, n. 3, p. 266-274, dez. 2014.

SCHILLING, A. C.; BATISTA, J. L. F.; COUTO, H. Z. Ausência de estabilização da curva de acumulação de espécies em florestas tropicais. Ciência Florestal, Santa Maria, v. 22, n. 1, p. 101-111, jan./mar. 2012.

SHEPHERD, G. J. Fitopac 2.1. Campinas: Universidade Estadual de Campinas, Departamento de Botânica, 2009.

VENTUROLI, F.; VENTUROLI, S. Recuperação florestal em uma área degradada pela exploração de areia no Distrito Federal. Ateliê Geográfico, Goiânia, v. 5, n. 1, p. 183-195, mar. 2011. 